\title{
ALARME DE INCÊNDIO COMO ESTRATÉGIA LEGISLATIVA: O CASO DA COMISSÃO DE DIREITOS HUMANOS E MINORIAS DA CÂMARA DE DEPUTADOS DO BRASIL
}

\section{FIRE ALARM AS A LEGISLATIVE STRATEGY: THE CASE OF THE COMMITTEE ON HUMAN RIGHTS AND MINORITIES OF THE BRAZILIAN DEPUTY CHAMBER \\ LA ALARMA DE INCENDIOS COMO UNA ESTRATEGIA LEGISLATIVA: EL CASO DEL COMITÉ DE DERECHOS HUMANOS Y MINORÍAS DE LA CÁMARA DE ADJUDICACIÓN BRASILEÑA}

\author{
Maria Cristina M. de F. Bacovis* \\ Fabiano Santos**
}

\begin{abstract}
Resumo: O artigo analisa a atuação da Comissão de Direitos Humanos e Minorias da Câmara dos Deputados do Brasil (CDHM) tendo como recorte temporal o período entre 1995 (ano de sua criação) até 2016, ou seja, entre as $50^{\mathrm{a}}$ e $55^{\mathrm{a}}$ legislaturas, combinando elementos conceituais dos campos jurídico e político a fim de esclarecer sobre suas estratégias com vistas ao avanço da agenda de direitos humanos no país. O estudo examina a atuação da CDHM sob a perspectiva do modelo do alarme de incêndio, isto é, argumenta que este modelo representa a melhor maneira de se entender porque a CDHM tornou-se uma das principais instituições do Legislativo brasileiro. Embora analiticamente fundamentado, este trabalho possui ambição e natureza descritiva, tendo como fio condutor o comportamento da CDHM no período analisado. O desenvolvimento do artigo ocorre por meio de duas seções: inicialmente discorre-se sobre a estratégia legislativa do alarme de incêndio resgatando a conceituação de McCubbins e Schwartz (1984) e a adaptando para o contexto político brasileiro; em seguida, aplica-se esse aparato conceitual para a análise de casos reais de reação legislativa, através da CDHM, a episódios de violação de direitos humanos no país.
\end{abstract}

Palavras-chaves: Comissões da Câmara dos Deputados; Direitos Humanos; Modelo de Alarme de Incêndio.

\begin{abstract}
The article analyses the activities of the Committee on human rights and minorities of the Brazilian Chamber of Deputies of Brazil (CDHM) from 1995 (when it was established) to 2016. It combines conceptual tools of laws with modern models of political analysis in order to clarify the committee's strategies towards enhancing the agenda of human rights in the country. The study exams the CDHM from the perspective of the fire alarm model, that is, it argues that this model is the best way to understand why this particular committee became one of the most important institutions within the Legislature. Although analytically based, this work has a descriptive nature and intent, with its leitmotiv relying on the CDHM's
\end{abstract}

\footnotetext{
*Professora pesquisadora na Universidade do Estado de Mato Grosso. E-mail: mcmfb@ hotmail.com

${ }^{* * *}$ Professor pesquisador no Instituto de Estudos Sociais e Políticos (IESP) da Universidade do Estado do Rio de Janeiro (UERJ). E-mail: fsantos@ iesp.uerj.br
} 
behavior during the period under analysis. The development of the article occurs through two main sections: we initially discuss the fire alarm as a legislative strategy, bringing in the conceptualization of McCubbins and Schwartz (1984), adapting the concept to the Brazilian political context; we then apply the conceptual framework to analyze real cases of legislative reaction, through CDHM activities, to human rights violation in the country.

Keywords: Committees in the Chamber of Deputies; Human Rights; Fire Alarm Model.

Resumen: El artículo analiza el desempeño de la Comisión de Derechos Humanos y Minorías de la Cámara de Diputados de Brasil (CDHM) tomando como corte temporal el período comprendido entre 1995 (año de su creación) hasta 2016, es decir, entre las legislaturas 50 y 55, combinando elementos conceptuales del campo legal y político para aclarar sus estrategias para avanzar en la agenda de derechos humanos en el país. El estudio examina el desempeño del CDHM desde la perspectiva del modelo de alarma contra incendios, es decir, argumenta que este modelo representa la mejor manera de entender por qué el CDHM se ha convertido en una de las principales instituciones de la Legislatura brasileña. Aunque analíticamente basado, este trabajo tiene ambición y naturaleza descriptiva, teniendo como guía el comportamiento de CDHM en el período analizado. El artículo se desarrolla a través de dos secciones: primero, discutimos la estrategia legislativa de la alarma de incendios, rescatando la conceptualización de McCubbins y Schwartz (1984) y adaptándola al contexto político brasileño; Este aparato conceptual se aplica luego al análisis de casos reales de reacción legislativa a través del CDHM a episodios de violaciones de derechos humanos en el país.

Palabras clave: Comisiones de la Cámara de Representantes; Derechos humanos; Modelo de alarma contra incendios

\section{Introdução}

As questões de direitos humanos, principalmente referentes aos grupos classificados como vulneráveis, assumiram grande relevância política e social no Brasil contemporâneo; assuntos que antigamente eram tabus hoje fazem parte do cotidiano. Temas como dignidade e igualdade, apresentam diferentes modos de compreensão pela sociedade e isso, muitas vezes, resulta em conflitos, cabendo ao Estado preveni-los e solucioná-los. Nesse contexto, escolher a CDHM como objeto de investigação nos parece contribuir tanto para as discussões no âmbito jurídico, quanto no da análise política stricto sensu, ademais de potencialmente agregar conhecimento para o estudo do sistema de comissões e suas estratégias de atuação no Legislativo brasileiro ${ }^{1}$.

Os temas afetos à CDHM, por tradição, estão presentes nas agendas dos partidos considerados de esquerda, tais como direito das mulheres, dos negros, dos índios, dos trabalhadores mais frágeis, bem como as condições desumanas vivenciadas nos presídios, dentre

\footnotetext{
${ }^{1}$ Para uma revisão da literatura sobre Legislativo no Brasil ver Figueiredo e Santos (2016).
} 
outros temas polêmicos. Assim, não é de se estranhar que, criada em 1995 teve, até 2016, 22 (vinte e dois) presidentes, sempre havendo alternância em sua direção entre partidos considerados como pertencente àquele campo político ${ }^{2}$. A exceção ocorre no ano de $2013^{3}$, quando um partido de extrema-direita disputou e assumiu a presidência da Comissão com o Deputado Federal, por São Paulo, Pastor Marco Feliciano do PSC, cabendo a vice-presidência também a esse partido com a Deputada Federal, pelo Acre, Antônia Lúcia. Grande polêmica instaura-se no mundo político, na medida em que se questionou sobre o porquê de um deputado/pastor, que, anteriormente havia declarado que "sobre o continente africano repousa a maldição do paganismo, ocultismo, misérias, doenças oriundas de lá: ebola, Aids, fome... etc" e escrito que "a podridão dos sentimentos dos homo afetivos leva ao ódio, ao crime e à rejeição" (NÉRI, 2013), naquele momento, disputava a presidência de uma Comissão cujo o objetivo e tradição sempre foram os de zelar pelos direitos de minorias. Por conta dessa intensa disputa, nos parece razoável levantar as seguintes indagações: por que a CDHM despertaria o interesse de partidos que, até então, a consideravam irrelevante? Se o diagnóstico corrente sobre a fraqueza do sistema de comissões no Brasil é correto, por que tanta disputa em torno da presidência desta Comissão em específico ${ }^{4}$ ? Em que sentido então teria a atuação da CDHM relevância política a ponto de ser objeto de ambição de bancadas agressivamente conservadoras?

Tendo estas questões em mente, no artigo que se segue investigamos a atuação da CDHM em momentos cruciais do debate político no país, especificamente suas ações frente a demandas de movimentos sociais pela concretização de direitos humanos, amparados por elementos conceituais dos campos jurídicos e político. Utilizamos para fins de análise o aparato conceitual da literatura sobre oversight, e a noção crucial de alarme de incêndio, tendo em vista compreender como a CDHM atuou constantemente para a visualização e vocalização das ameaças e violações aos direitos humanos.

É útil lembrar que o termo fire alarm (alarme de incêndio) foi conceitualmente trazido para o campo da ciência política por McCubbins e Schwartz (1984); trata-se de um sistema de regras, procedimentos e práticas no âmbito do Poder Legislativo que (no presente trabalho, em se tratando de direitos humanos, como argumentaremos) permite aos cidadãos e aos grupos de interesse desvelar questões referentes às ameaças e violações de seus interesses (no caso deste artigo, esse conjunto de direitos), bem como postular a implementação de políticas públicas que satisfaçam as demandas nesse sentido. Argumentamos então que a correta caracterização do comportamento da comissão advém da aplicação contextualizada do conceito de alarme de incêndio, o que permite também a origem de sua eficiência e o motivo de ter sido objeto de intensa

\footnotetext{
${ }^{2} \mathrm{O}$ PT foi o partido que mais vezes ocupou a presidência, 15 (quinze) vezes, seguido do PDT (quatro), 4 vezes e depois PCdoB, 1 (uma) vez.

${ }^{3}$ Breve passagem do PTB também havia ocorrido anteriormente, mas em contexto político de baixa polarização com relação à agenda básica da Comissão.

${ }^{4}$ Ver os trabalhos muito citados de Figueiredo e Limongi (1995); e, Pereira e Mueller (2000).
} 
disputa em passado recente. A fim de mostrar a plausibilidade do argumento utilizamos a metodologia de estudos de casos exemplares.

Dividimos o artigo em duas seções; inicialmente discorre-se sobre a estratégia legislativa do alarme de incêndio trazendo a conceituação de McCubbins e Schwartz (1984) e o estudo de autores brasileiros sobre tema; a seguir, pontuam-se alguns aspectos sobre as fontes materiais dos direitos humanos identificadas como alarmes de incêndio na esfera comissional.

\section{Alarme de incêndio como estratégia legislativa}

A expressão alarme de incêndio, no contexto da ciência política, foi cunhado por McCubbins e Shwartz (1984) ao estudarem a competência do Congresso americano em fiscalizar/supervisionar as ações do Poder Executivo e do próprio Legislativo.

O estudo de McCubbins e Shwartz (1984) contesta a afirmação de que o Congresso negligencia a competência de fiscalizar/supervisionar o Executivo. Essa denegação parte da concepção de que há mais de uma opção para efetivar essa competência. Os autores enunciam então duas categorias: supervisão-patrulha de polícia e supervisão alarme de incêndio; a primeira referindo-se a mecanismos centralizados para examinar diretamente as atividades do Executivo, a segunda elegendo procedimentos descentralizados e práticas que permitam cidadãos e grupos de interesse organizados examinarem decisões administrativas. O ponto relevante do trabalho de McCubbins e Shwartz (1984) é considerar a lógica do alarme de incêndio como uma escolha racional dos parlamentares em detrimento à supervisão do tipo patrulha de polícia.

O modelo criado por esses autores fundamenta-se em 3 (três) pressupostos: tecnológico, motivacional e institucional, dos quais derivam algumas consequências.

O pressuposto tecnológico refere-se à possibilidade de o Congresso escolher entre as duas formas de supervisão disponíveis ou combinar as duas opções fazendo trocas e interações entre elas. Os autores exemplificam dois momentos em que podem ocorrer essa combinação de recursos: durante a produção legislativa e da função de fiscalização. No primeiro caso, o Congresso pode incluir mecanismos de patrulha policial ou de alarme de incêndio como requisitos para audiências públicas que fundamentarão o processo legislativo. $\mathrm{Na}$ função fiscalizadora, o Congresso, ao avaliar o desempenho de uma agência, pode realizar audiências públicas para patrulhar por violações de metas legislativas ou esperar por alarmes para sinalizar possíveis violações. (MCCUBBINS; SHWARTZ, 1984).

O pressuposto motivacional refere-se ao fato de que um congressista busca a maximização dos créditos que recebe pelos benefícios distribuídos a seus apoiadores, cidadãos e/ou grupos de interesse, dentro de seu círculo eleitoral ou não, cujo apoio pode ajudá-lo a conquistar a reeleição. (MCCUBBINS; SHWARTZ, 1984).

$\mathrm{O}$ pressuposto institucional diz respeito à atuação das agências do estado como agentes do Congresso, em especial das comissões e subcomissões das quais dependem para autorizações 
e dotações. (MCCUBBINS; SHWARTZ, 1984).

Como consequência desses pressupostos, McCubbins e Shwartz (1984) afirmam que a supervisão alarme de incêndio seria mais eficiente como estratégia para obtenção de crédito, primeiramente porque a supervisão patrulha de polícia despende mais tempo para examinar as ações do Executivo, bem como para encontrar e sanar desvios e/ou violações nas metas legislativas, enquanto que a supervisão alarme de incêndio permite que os congressistas utilizem o tempo em outras atividades.

Além disso, com referência aos gastos financeiros ambas as supervisões podem ter o mesmo custo, contudo no caso do alarme de incêndio é dividido com os atores que soam o alarme, por exemplo os grupos de interesse. Desse modo, o congressista, ao optar pela lógica do alarme de incêndio, tem gasto mais baixo e obtém créditos por sua reação ao alarme. (MCCUBBINS; SHWARTZ, 1984).

No Brasil, dois estudos destacam-se ao tratar da supervisão alarme de incêndio: Octavio Amorim Neto e Paulo Tafner (2002) escreveram sobre governos de coalizão e mecanismos de alarme de incêndio no controle legislativo das medidas provisórias e Helga do Nascimento de Almeida (2016) pesquisou sobre representantes, representados e as redes sociais privadas. Amorim Neto e Tafner destacam que:

[...] um dos mecanismos de monitoramento mais utilizados por mandantes em regime democráticos, é o uso de alarmes de incêndio. Nesse caso, não é preciso que o Congresso possua grandes conhecimentos técnicos para saber se um MP vai ou não ao encontro de seu interesse. Basta que o Congresso ouça as partes que serão afetadas por uma MP para que saiba se ela é a melhor do que o status quo (AMORIM NETO; TAFNER, 2002, p. 20).

Percebe-se que a lógica do alarme de incêndio presta-se ao ganho informacional pelos congressistas que muitas vezes não possuem conhecimento técnico a respeito das matérias discutidas.

Amorim Neto e Tafner (2002) exemplificam o uso da supervisão alarme de incêndio quando da edição, em 1997, do chamado Pacote 51, conjunto de medidas fiscais tais como aumento de impostos e corte de gastos, lançado pelo presidente Fernando Henrique Cardoso e seu Ministro da Fazenda Pedro Malan, com o objetivo de reduzir o déficit fiscal do país. Na ocasião, vários setores da sociedade manifestaram sua contrariedade à proposta do Executivo.

[...] após verificar que a oposição da classe média era intensa, ou seja, após a ativação do alarme de incêndio, é que o Congresso se armou de uma estratégia consistente para lidar com o pacote fiscal. [...] depois de algumas rodadas de negociação, representantes do Executivo e do Legislativo, finalmente fecharam um acordo estabelecendo um aumento da alíquota do imposto de renda mais aceitável para a classe média (AMORIM NETO; TAFNER, 2002, p. 21).

Os autores referidos esclarecem que durante o período examinado (basicamente os anos 
de governos do PSDB liderados por Fernando Henrique Cardoso) um grande número de Medidas Provisórias que são reeditadas como resultado de uma escolha racional da maioria parlamentar no que concerne à maneira mais eficaz de obter informações sobre seus efeitos. (AMORIM NETO; TAFNER, 2002). Ou seja, como consequência do alarme de incêndio acionado pelos destinatários das MP.

O estudo de Helga do Nascimento de Almeida (2016) diz respeito às redes sociais, Facebook e Twiter, como ferramentas de supervisão alarme de incêndio.

Os representados [cidadãos, grupos de interesse, dentre outros] podem ocupar o papel de agentes, nos contextos digitais e soarem alarmes de incêndio, oferecendo assim um ganho informacional para os mandantes (os representantes) e para o jogo político de forma geral (ALMEIDA, 2016, p. 1).

Para Almeida (2016), os representantes somente dirigem sua atenção aos temas que forem trazidos à tona pelo alarme de incêndio, ou seja, os parlamentares dirigem sua atenção e trabalho aos assuntos que tenham repercussão junto aos eleitores.

O modelo de análise da autora pauta-se na premissa de que tanto parlamentares quanto os representados teriam ganhos com a utilização das redes sociais da internet como mecanismo de alarme de incêndio.

Parlamentares utilizariam o mecanismo e alarme de incêndio em suas redes sociais privadas com pretensões informacionais, ou seja, para diminuírem o déficit informacional vivido por eles dentro do Congresso. [Os representados] assumiriam aqui o papel de agentes, a possibilidade de soar o alarme de incêndio e de, então, fazer com que agendas que lhes interessem emerjam, trazendo novas informações (ALMEIDA, 2016, p. 5).

Nesse prisma, amplia-se a percepção sobre a lógica do alarme de incêndio. Se a concepção inicial era a de supervisão/fiscalização do Poder Executivo, o que bem exemplificaram Amorim Neto e Tafner (2002) quando do estudo sobre as medidas provisórias, agora passa-se a entender o alarme de incêndio como instrumento de propagação de informações, o que proporciona ganho informacional ao parlamentar e adequação da agenda do legislativo aos interesses sociais.

Entendendo-se que a Comissão de Direitos Humanos e Minorias da Câmara dos Deputados (CDHM) exerce uma função importante no que diz respeito à visibilidade e vocalização de ameaças e violações de Direitos Humanos no Brasil eis que procede, como argumentamos neste artigo, sob a perspectiva de alarme de incêndio. Contudo, esse entendimento requer que as concepções sobre a lógica do alarme de incêndio sejam entendidas numa perspectiva aglutinadora.

A CDHM, em sua competência de fiscalização, utiliza o alarme de incêndio para apurar se há desvio de finalidade nas políticas públicas implementadas e ao mesmo tempo verifica quando determinada política, sendo necessária, deixa de ser criada e/ou executada. Além disso a 
Comissão serve-se dessa abordagem como mecanismo essencial à aquisição de informação sobre ameaças e violações de direitos humanos no Brasil.

Tendo em vista essa concepção integradora, de fiscalização e de ganho informacional, cumpre esclarecer sobre outro aspecto da lógica de alarme de incêndio quando se trata da CDHM.

A analogia entre o alarme de incêndio, considerado literalmente, e a expressão utilizada na bibliografia básica da ciência política de estudos legislativos no Brasil, no caso da CDHM, necessita de certa complementação. Os exemplos trazidos anteriormente mostram aspectos interessantes e corretos, porém dotados de certa imobilidade.

Transparece que, após soar o alarme, encontra-se uma resposta e que nesse momento ele cumpriu sua função, assim como o alarme de incêndio real cumpre sua tarefa com a chegada dos bombeiros. Por exemplo, o Plano 51 foi reeditado após a insatisfação da classe média ser percebida, assim como, constatou-se que parlamentares ajustam suas agendas após manifestações nas redes sociais. Ocorre que o alarme de incêndio, no cenário da CDHM, só pode ser entendido de forma dinâmica, como parte de um fluxo que se auto alimenta.

A estrutura da CDHM contém mecanismos aptos a proporcionar a vocalização de ameaças ou violações de direitos humanos (alarme de incêndio), tais como sistema de recebimento de denúncias, audiências públicas, campanhas e conferências.

Ao soar o alarme de incêndio, pela voz da sociedade e por meio dos instrumentos disponibilizados pela CDHM, esta Comissão opera em várias direções e pode, por si ou por um de seus membros, tomar iniciativa de lei em sentido amplo e/ou ela própria passa a vocalizar as questões relativas aos direitos humanos, ou seja, passa a soar o alarme de incêndio por si mesma acionando autoridades competentes para resolução do fato, informando a outros parlamentares sobre essas situações, levando casos para organismos internacionais, ou mesmo alertando a própria sociedade sobre determinadas ocorrências.

Fica claro que, ao mesmo tempo que a CDHM é receptora do alarme de incêndio acionado por indivíduos, grupos de interesse ou sociedade em geral, tendo assim ganho informacional, ela também atua soando o alarme, vocalizando as ocorrências de ameaça ou violação de direitos humanos, proporcionando, aos demais parlamentares, informações pertinentes aos direitos humanos, desvelando esses temas para a sociedade em geral e também acionando autoridades para solução de conflitos desse cenário.

Nessa perspectiva, entende-se que embora algumas vezes as atribuições da CDHM possam parecer negligenciadas, na verdade a Comissão exerce papel importante ao proporcionar mecanismos de alarme de incêndio para a manifestação daqueles que tiveram seus direitos ameaçados ou violados, bem como a ela mesma soar o alarme para destinatários competentes à resposta adequada.

A seguir tratamos sobre as fontes materiais dos direitos humanos. Essas fontes nada mais são do que o alarme de incêndio acionado no interior da sociedade, refletindo as questões 
referentes às ameaças e violações desses direitos que, no exercício de sua racionalidade política, os membros da CDHM acabaram enfrentando. Em seguida, na mesma seção, passamos aos relatos dos casos típicos da política de alarme de incêndio no âmbito da comissão.

\section{Soando o alarme de incêndio: fontes materiais dos direitos humanos no âmbito da Comissão de Direitos Humanos e Minorias da Câmera dos Deputados}

Entende-se que a CDHM conecta os anseios sociais às autoridades competentes para a realização de políticas públicas, produção legislativa adequada e decisões de lides referentes aos temas dos direitos humanos e minorias. Dessa forma, é o órgão da estrutura legislativa brasileira que precipuamente alerta sobre os problemas relativos aos direitos humanos, adotando estratégias que priorizam o debate e a participação pública.

Cabe ao legislador interpretar e atender as demandas sociais compreendendo-as como fontes primárias que dão conteúdo às normas por eles criadas. As questões vivenciadas pela sociedade, em especial no que tange às ameaças e violações de direitos humanos, soam como alarmes de incêndio, proporcionando um ganho informacional ao parlamentar. O legislador, por meio do processo legislativo, integra matéria e forma, fornecendo à sociedade regras formais de condutas fundamentadas em seus anseios.

François Geny classificou as fontes jurídicas em duas espécies: substanciais e formais. As fontes substanciais, também denominadas de fontes materiais, correspondendo, dentre outros, aos elementos sociais, históricos, ideais, culturais de um povo. As fontes formais correspondendo à elaboração técnico-solene daquilo que é fornecido pelas primeiras. (FERRAZ JÚNIOR, 2007).

Essa divisão dual das fontes do Direito é utilizada até hoje e reflete o caráter integrativo entre aquilo que emana da sociedade e a formalidade que transforma as demandas sociais em regras jurídicas. Este artigo alude às fontes materiais na esfera de ação da CDHM, identificandoas como alarmes de incêndio determinantes de sua atuação.

Fonte material ou subjetiva tem sentido imediato, refere-se aos acontecimentos e fenômenos sociais que de uma forma ou outra requerem um tratamento formal por parte do legislador, refere-se ao conteúdo da norma. Há que se destacar que os direitos humanos "refletem um construído axiológico, a partir de um espaço simbólico de luta e ação social" (PIOVESAN, 2011, p. 220).

Entende-se que a matriz dos direitos humanos são as relações sociais refletidas historicamente, a efervescência da sociedade na relação tempo e espaço, por exemplo, os movimentos pelo fim de novos formatos de trabalho escravo, pelo reconhecimento de direitos da criança e do adolescente, pelo fim da violência contra as mulheres, contra o racismo, pelos direitos dos deficientes, dentre outros alarmes de incêndio, que refletem diretamente na produção legislativa no Brasil. 
A análise empírica que relataremos abaixo refere-se a casos típicos da política do alarme de incêndio no contexto da CDHM. Desdobramos a pesquisa revela-se em duas diretrizes: as denúncias de ameaças e/ou violações dos direitos humanos e a participação pública; esta, por trazer à tona o debate referente a assuntos que necessitam de mais informações para sua compreensão, aquelas, por demonstrarem a situação brasileira no que se refere aos direitos humanos, ambas, instrumentos de vocalização das ameaças e violações a esses direitos.

\subsection{Denúncias}

A leitura dos relatórios de atividades da CDHM referentes às sessões legislativas de 1995 a 2016, mostra o número de denúncias protocoladas perante a Comissão, contudo alguns de seus relatórios, notadamente após a sessão legislativa de 2008, deixaram de elencar as denúncias e registrar sua quantidade, utilizando-se de expressões tais como "inúmeras denúncias" ou “centenas de denúncias" para se referirem as mesmas.

No período de 1995 a 2008 foram protocoladas 4888 (quatro mil oitocentos e oitenta e oito) denúncias, sendo que a categoria elencada nos relatórios da CDHM que mais teve denúncias foi a de "presos e prisões" com 17,24\%, seguidas pelas categorias "arbitrariedade policial" com $7,4 \%$, assassinatos com 6,5\% e ameaças com 5,6\% do total de denúncias nesse período. Destaca, novamente, que após a sessão legislativa de 2008 até a sessão legislativa de 2016, os relatórios da Comissão não elencaram as categorias e nem o número de denúncias. Alguns casos de denúncias tornaram-se emblemáticos por sua gravidade, tais como assassinatos, tortura, chacinas, falta de condições carcerárias básicas, ação de grupos de extermínio, conflitos agrários e violência policial. A seguir serão relatados alguns desses casos que exemplificam o caráter de alarme de incêndio nas condutas da CDHM.

O massacre de Corumbiara é um exemplo da ação da CDHM, na perspectiva de alarme de incêndio. Em 9 de agosto de 1995, a Comissão recebeu a denúncia da ocorrência de conflitos entre policiais e posseiros na Fazenda Santa Elina, em Corumbiara, em Rondônia. Após deliberação, solicitou-se urgência na formação de uma Comissão Especial da Câmara para verificar a situação de perto. A Comissão Especial verificou que 180 (cento e oitenta) policiais, ao executarem o mandado de reintegração de posse, utilizaram armas, bombas de iluminação e gás lacrimogênio, resultando na morte de 10 (dez) pessoas, 8 (oito) desaparecidos e dezenas de feridos. A CDHM buscou junto ao Conselho de Direitos da Pessoa Humana (CDDPH) apurar a responsabilidade e lutar contra a impunidade dos responsáveis. (BRASIL, 1996).

A partir do massacre de Corumbiara, a CDHM dirigiu sua atenção a outros conflitos agrários como o massacre de Eldorado de Carajás, do qual acompanhou os fatos relativos ao inquérito, além disso, nesse e em outros conflitos agrários a Comissão procurou promover medidas que evitassem as violações de direitos humanos e a impunidade. Sendo que sua atuação nessa área se deu em conjunto com o Fórum Nacional contra a Violência no Campo. (BRASIL, 
1997).

A CDHM, em 2001, recebeu denúncia de que uma série de assassinatos de meninos entre 9 (nove) e 15 (quinze) anos de idade, que acontecia, desde 1991, em Paço do Lumiar, município próximo à capital do Maranhão. Antes de serem assassinados esses meninos tiveram seus órgãos genitais, olhos, língua e dedos extirpados; também havia nos corpos indícios de violência sexual. Somente 2 (dois) casos haviam sido solucionados até então. A Comissão requereu ao governo estadual do Maranhão a averiguação do porquê da impunidade nesses crimes. (BRASIL, 2002).

A Comissão, em 2002, acompanhou o caso de tortura em Patrocínio, em Minas Gerais, no qual as famílias de vítimas denunciaram a brutalidade e ilegalidade de ações de detetives e delegado da cidade. Constatou-se que, após o afastamento, os acusados foram reconduzidos ao serviço por portaria do Delegado Regional e Corregedor da Polícia. A CDHM oficiou ao Secretário Estadual de Segurança Pública, à Secretaria Adjunta de Direitos Humanos, ao Programa Federal de Proteção à testemunha, à Procuradoria Geral de Justiça e à Ouvidoria da Polícia de Minas Gerais, solicitando informações e providencias. (BRASIL, 2003).

Um dos casos que exemplifica a ação da CDHM, em 2008, refere-se à denúncia de um caso de tortura de uma menina de 12 (doze) anos, em que a acusada é uma empresária e dona da casa onde a menina vivia. Após diligência de um grupo de membros da CDHM, que constatou maus-tratos e cárcere privado da menina, a criança foi encaminhada e atendida por médico e psicólogo. Foi aberto inquérito na Delegacia de Proteção à Criança e ao Adolescente (DPCA). (BRASIL, 2009).

Em 2011, receberam destaque pela CDHM, as denúncias de ameaças contra militantes de direitos humanos e empresas jornalísticas em Goiás. Foram registradas situações de ameaças graves, pressões e constrangimentos. Os autores desses crimes são policiais que também são acusados de participar de um grupo responsável por desaparecimentos de jovens. A CDHM solicitou ao governador de Goiás a adoção de medidas estruturais contra a impunidade nos crimes de extermínio, além da ação de educação e cultura em direitos humanos na formação dos agentes públicos de segurança pública. (BRASIL, 2012).

Na perspectiva de vocalização sobre violações e ameaças de direitos humanos, um ponto importante a ser lembrado é a inclusão de uma ferramenta de comunicação de ameaças ou violações de direitos humanos na página da CDHM na internet a partir de julho de 2011. Segundo o relatório da CDHM, referente à sessão legislativa de 2012 entre 13 de julho de 2011 e 31 de dezembro de 2012, a Comissão recebeu um total de 838 comunicados sobre violações dos direitos de crianças e adolescentes, homofobia, racismo e intolerância religiosa. (BRASIL, 2013).

Mais uma vez, exercendo sua função de acionar alarme de incêndio, em 2014, a CDHM solicitou providencias a órgãos governamentais sobre os conflitos fundiários envolvendo populações indígenas, como o caso daqueles que receberam ameaças por apoiarem demarcações em Santa Catarina. Em outro caso, a CDHM intermediou para que o cacique Babau, de Olivença, 
na Bahia, preso em Brasília, não fosse transferido para Bahia onde poderia sofrer violência na prisão. (BRASIL, 2015).

Nesses e em outros casos, a CDHM, após as denúncias recebidas tomou diferentes medidas, tais como, acompanhamento de investigações, encaminhamento de requerimentos aos órgãos encarregados de investigação, visitas às comunidades ameaçadas, realização de audiências públicas, acompanhamento de negociações pertinentes a cada caso. Pode-se afirmar que a CDHM agiu, nos casos relatados, como receptora de muitos alarmes de incêndio, bem como acionou muitos deles.

\subsection{Participação pública}

Pode-se afirmar que outro instrumento utilizado como acionador de alarmes de incêndio, no âmbito da CDHM, é a participação pública, ideia de que para a resolução das demandas deve se dar ênfase à cooperação entre Estado e sociedade por meio da cooperação de diferentes segmentos sociais na formulação, execução e fiscalização de políticas públicas.

Segundo boa parte da literatura em análise política ${ }^{5}$, participação possui caráter educativo-pedagógico, representando a possibilidade de constituição de um espaço privilegiado no qual se pode expressar desejos e necessidades, construir argumentos, formular propostas, ouvir outros pontos de vista, reagir, debater e chegar a consensos. Um espaço em que a construção dialogada do interesse público passa a ser objetivo de todos. Sob esse prisma, afirma-se que os mecanismos participativos desejáveis para as demandas contemporâneas, em especial em direitos humanos, além de legitimar cidadãos, organizados ou não, como sujeitos partícipes, deve: propiciar espaço para discussões sobre assuntos afetos à população em geral, aos vulneráveis e às minorias; proporcionar informações sobre temas a serem discutidos e decididos; assim como, influenciar as escolhas daqueles que têm poder decisório, ou seja, o locus participativo estimula o soar dos alarmes de incêndio.

A CDHM tradicionalmente promove a participação pública em eventos que proporcionam o debate sobre os direitos humanos, permitindo a visualização e vocalização de ameaças e violações desses direitos. Esses eventos podem ser analisados sob dois prismas: eventos autorizados por força do artigo 24, XIII, do RICD, que prevê que cabe às comissões, em razão da matéria, "estudar qualquer assunto compreendido no respectivo campo temático ou área de atividade, podendo promover em seu âmbito, conferencias, exposições, palestras ou seminários;" entende-se esse rol como exemplificativo e aqui esses eventos serão chamados de eventos gerais; e, de outro lado, eventos fundamentados no artigo $58, \S 2^{\circ}$., II da Constituição Federal e artigo 24, III, do RICD, ambos prevendo que as comissões têm competência para

\footnotetext{
${ }^{5}$ Para uma boa análise a respeito das boas consequências advindas de processos participativos e deliberativos sobre o processo legislativo, ver Pogrebinschi e Santos (2011) e Rocha (2016). Na literatura jurídica, um ótimo exemplo encontra-se em Moroni (2009, p. 122).
} 
realizar audiências públicas com a participação da sociedade civil.

No primeiro caso, a CDHM realizou seminários, palestras, campanhas, caravanas, fóruns, palestras, lançamento de livros, conferências (aqui no sentido de reunião sobre determinado tema), jornadas, júris-simulados, encontros e lançamentos de livros e outras mídias. ${ }^{6}$ No segundo caso, tem realizado audiências públicas em todas as suas sessões legislativas. A seguir, com o intuito de exemplificar o entendimento da participação pública como instrumento de alarme de incêndio, serão relatados alguns desses eventos.

A CDHM, no período pesquisado, realizou 28 (vinte e oito) campanhas dentre as quais destacam-se: Comitê Galdino: luta pela causa indígena; Campanha Informativa sobre Direitos Humanos; Natal na paz, sem morte, sem fome; Manifesto 2000 - cultura da paz e não violência; Campanha nacional contra a tortura; e, ativismo contra a violência contra a mulher. Note-se que as campanhas sempre objetivaram levar ao público temas marcadamente com muitas ameaças e violências aos direitos humanos.

Desde sua criação até 2016, a Comissão realizou 16 (dezesseis) conferências, destacandose a I Conferência Nacional de Direitos Humanos, em 1996, com a participação de 150 (cento e cinquenta) entidades, teve como objetivo analisar o anteprojeto do Programa Nacional de Direitos Humanos (PNDH). A Conferência resultou em propostas para o anteprojeto analisado, bem como com o comprometimento da CDHM articular e fiscalizar a sua implementação. (BRASIL, 1997). Essa Conferência pode ser considerada um marco importante na trajetória dos direitos humanos no Brasil, pois foi o primeiro debate amplo promovido sobre o tema por uma instituição pública. Outras conferências sobre temas variados tiveram lugar na CDHM, a violência, o sistema prisional, os direitos das mulheres foram alguns dos assuntos tratados nas conferências.

Entre as sessões legislativas de 1995 e 2016, a CDHM realizou 111 (cento e onze) seminários de modo que criou um círculo de debates com amplo espectro temático. Segurança pública, doença do trabalho, direito dos deficientes, alimentação, políticas afirmativas, educação para os direitos humanos, violência contra mulheres, violência intrafamiliar, direitos dos homossexuais, crianças e adolescentes, dependência química e tratamento adequado, racismo, idosos e saúde mental foram alguns dos temas debatidos nesse formato de participação pública.

Com referência às audiências públicas destaca-se que as mesmas estão previstas na legislação brasileira como um mecanismo de participação de caráter opinativo não vinculante, mas que se consolida como importante instrumento na área de direitos humanos a partir da necessidade de atuação conjunta do Estado e da sociedade para a criação de uma cultura em direitos humanos.

\footnotetext{
${ }^{6}$ Destaca-se o "Seminário Faces da Violência Contra a Mulher: uma Realidade que Afeta todos nós" teve como objetivo discutir a situação da mulher no Brasil. No qual a deputada Luiza Erundina afirmou que "enquanto não houver um diagnóstico completo [sobre a violência contra as mulheres], as políticas públicas continuarão pontuais ... Isso impede uma posição de enfrentamento contra os agressores" Também o deputado Jean Willys destacou que " a violência obstétrica foi reconhecida como uma das formas modernas de agressão contra a mulher"
} 
A audiência pública é um instrumento que leva a uma decisão política ou legal com legitimidade e transparência. Cuida-se de uma instância no processo de tomada de decisão administrativa ou legislativa, através da qual a autoridade competente abre espaço para que todas as pessoas que possam sofrer os reflexos dessa decisão tenham oportunidade de se manifestar antes do desfecho do processo. É através dela que o responsável pela decisão tem acesso, simultaneamente e em condições de igualdade, às mais variadas opiniões sobre a matéria debatida, em contato direto com os interessados. Tais opiniões não vinculam a decisão, visto que tem caráter consultivo, e a autoridade, embora não esteja obrigada a segui-las, deve analisa-las segundo seus critérios, acolhendo-as ou rejeitando-as. (SOARES, 2002, p. 260).

No campo jurídico, Moreira Neto (1991), destaca que a realização de audiências públicas, mesmo que estas não tenham poder vinculante, gera uma série de efeitos político-jurídicos, quais sejam:

- Evidencia a intenção [...] de produzir a melhor decisão;

- Galvaniza o consenso em reforço da decisão que vier a ser tomada;

- Manifesta o cuidado com a transparência [...];

- Renova permanentemente o diálogo entre agentes eleitos e seus eleitores;

- Presença de um forte conteúdo pedagógico, como técnica social de acesso ao poder e ao exercício do poder (MOREIRA NETO, 1991, p. 211).

Em se tratando do Poder Legislativo brasileiro, o Regimento Interno da Câmara dos Deputados prevê, em seu Título VIII que trata “da participação da sociedade civil”, no Capítulo III, a realização de audiências públicas, sua sistemática e seus objetivos.

No uso dessa prerrogativa, a CDHM realizou, no período pesquisado, mais de 400 (quatrocentas) audiências públicas, conforme registrado em seus relatórios de atividade e ilustrados na Tabela 1.

Tabela 1 - Número de audiências públicas por sessão legislativa e legislatura

\begin{tabular}{|c|c|c|c|c|c|c|}
\hline \multirow[t]{2}{*}{ Legislaturas } & \multicolumn{4}{|c|}{ Sessões legislativas } & & \multirow[b]{2}{*}{ Total por legislatura } \\
\hline & $\mathbf{1}^{\mathrm{a}}$ & $2^{a}$ & $3^{\mathbf{a}}$ & $4^{a}$ & & \\
\hline $50^{\mathbf{a}}$ & 14 & 17 & 16 & 18 & & 65 \\
\hline $51^{a}$ & 33 & 9 & 25 & 6 & & 73 \\
\hline $52^{\mathrm{a}}$ & 23 & 14 & 19 & 9 & & 65 \\
\hline $53^{\mathbf{a}}$ & 24 & 17 & 32 & 10 & & 83 \\
\hline $54^{\mathrm{a}}$ & 21 & 16 & 23 & 25 & & 85 \\
\hline $55^{\mathrm{a}}$ & 32 & & & - & - & 32 \\
\hline TOTAL & & & & & & 403 \\
\hline
\end{tabular}

Fonte: elaboração própria com base nos relatórios anuais da Comissão de Direitos Humanos da Câmara dos Deputados.

Com o objetivo de mostrar a dinâmica das audiências públicas no interior da CDHM, a seguir tratar-se-á das audiências que tiveram como objeto as questões referentes aos indígenas. Esse recorte metodológico justifica-se não só pelo grande número de audiências realizadas no interior da Comissão, o que impossibilita discorrer sobre todas elas, como também por se tratar 
de grupo minoritário e vulnerável.

Numa mostra sobre a sistemática das audiências e o posicionamento da CDHM frente aos direitos humanos indígenas, dois temas serão aqui rapidamente abordados: a saúde e a demarcação de terras. Assim, serão relatadas 2 (duas) audiências públicas: uma que tratou da saúde indígena e outra sobre a demarcação de terras indígenas.

A saúde indígena no Amapá foi objeto da audiência pública realizada em 5 de agosto de 2014, com patrocínio da CDHM e da Comissão de Direitos Humanos do Senado Federal e teve como objetivo o esclarecimento sobre denúncias recebidas sobre o atendimento inadequado à saúde indígena, no Amapá. Foram relatadas as faltas de servidores públicos qualificados, de profissionais de saúde, de medicamentos e de leitos para internação. (BRASIL, 2015).

Sobre a demarcação de terras indígena destaca-se a audiência pública realizada em maio de 2014, conjuntamente pela CDHM e a Comissão de Direitos Humanos do Senado Federal, com o apoio da Frente Parlamentar em Defesa dos Povos Indígenas, que debateu a situação das demarcações de terras indígenas e os conflitos agrários. (BRASIL, 2015). Na ocasião, foram ouvidos depoimentos de indígenas e agricultores. Após ponderações sobre o tema, os deputados comprometeram-se em mediar as negociações nos casos mais graves.

A CDHM realizou, entre 1995 e 2015, 23 (vinte e três) audiências públicas referentes aos indígenas, ou seja, 5,7\% das audiências públicas realizadas pela CDHM nesse período versaram sobre essas questões. Num primeiro olhar, parece pouco diante de tantos temas a serem discutidos nessa temática, contudo, há que se lembrar de que os assuntos a serem discutidos nessa Comissão são inúmeros e dizem respeito, também, a tantos outros grupos vulneráveis.

\section{Considerações finais}

A atualidade traz situações nas quais os direitos humanos são constantemente ameaçados e/ou violados. Tais questões deveriam ser enfrentadas pelos três Poderes, como exemplo as situações carcerária e indígena; contudo, observa-se que há, em linhas gerais, uma paralização institucional ao tratar desses temas.

Sabendo-se disso e identificando as comissões parlamentares como elementos estruturantes da atividade legislativa brasileira, a pesquisa pretendeu identificar qual o papel da Comissão de Direitos Humanos e Minorias da Câmara dos Deputados (CDHM), no cenário das lutas sociais pela dignidade.

A estratégia adotada no artigo trilhou dois caminhos complementares, inicialmente por meio de pesquisa bibliográfica, em especial sobre a estratégia legislativa do alarme de incêndio com destaque para a conceituação de McCubbins e Schwartz (1984) e sua contextualização para o Legislativo brasileiro; a seguir, por meio de pesquisa documental, foram analisados relatórios e atas da CDHM sob a perspectiva metodológica do estudo de casos a fim de identificar as estratégias legislativas aplicadas pela CHM. 
A ideia aqui desenvolvida foi a de que a CDHM, dentro da estrutura parlamentar, é um órgão bastante coerente e que desde sua criação age sob a perspectiva de lutar pela concretização dos direitos humanos no Brasil, desempenhando papel importante no que diz respeito à visibilidade e vocalização de ameaças e violações de direitos humanos no Brasil, sendo essa uma de suas principais funções eis que procede sob a perspectiva de alarme de incêndio.

Discorreu-se sobre a lógica do alarme de incêndio na moderna análise política, destacando que esta é uma opção racional do parlamentar na qual são disponibilizados mecanismos para que os envolvidos em situações de ameaça ou violações de direitos humanos manifestem-se dando conhecimento dessas questões aos grupos interessados, possibilitando também ganho informacional ao conjunto da Casa Legislativa; a seguir, identificaram-se as fontes materiais e formais dos direitos humanos e sua relação com a Comissão. Como fontes materiais, destacam-se as denúncias recebidas e a participação pública, principalmente nas audiências públicas.

A CDHM demonstrou compreender os direitos humanos como a luta contínua pela realização plena da condição humana e pelo fim da injustiças sociais, arbitrariedades e discriminações ainda tão presentes nos dias atuais. Nesse entendimento, como se viu no decorrer desse trabalho, a Comissão exerceu papel importantíssimo no que concerne a tornar visível e conhecidas as ameaças e violações de direitos humanos em todo país, sendo essencial na interpretação dos alarmes de incêndio para que as informações sejam disseminadas tanto do âmbito interno da Câmara dos Deputados, como para a sociedade em geral. Não foi por motivo então que forças políticas contrárias ao avanço desta agenda tenham se mobilizado e organizado tendo em vista alcançar sua presidência. Entendemos que essa é uma contribuição importante tanto para a ciência política dedicada ao estudo das instituições, em geral, e do Legislativo, em particular, quanto para ciência do direito, particularmente no que tange aos estudos sobre os meios pelos quais o estado busca a realização pratica dos direitos humanos e de minorias.

\section{Referências}

ALMEIDA, H. D. N. D. Representantes, representados e as redes sociais privadas. Propondo um modelo analítico para pensar a emersão de agendas no interior das páginas de parlamentares brasileiros no Facebook e Twiter. In: ENCONTRO ANUAL DA ASSOCIAÇÃO NACIONAL DOS PROGRAMS DE PÓS-GRADUAÇÃO EM CIÊNCIAS SOCIAIS (ANPOCS), 40. 2016, Caxambú. Anais [...], São Paulo: ANPOCS, 2016.

AMORIM NETO, O.; TAFNER, P. Governos de coalizão e mecanismos de alarme de incêndio no controle legislativo das medidas provisórias. Dados, Rio de Janeiro, v.45, n.1, p. 5-38, 2002.

BRASIL. Câmara dos Deputados. Relatório Anual da Comissão de Direitos Humanos e

Minorias. Brasília: Câmara dos Deputados, 1996. 42 p.

Câmara dos Deputados. Relatório Anual da Comissão de Direitos Humanos e

Minorias. Brasília: Câmara dos Deputados, 1997. 55 p. 
Câmara dos Deputados. Relatório Anual da Comissão de Direitos Humanos e

Minorias. Brasília: Câmara dos Deputados, 1998. 119 p.

Câmara dos Deputados. Relatório Anual da Comissão de Direitos Humanos e

Minorias. Brasília: Câmara dos Deputados, 1999. 73 p.

Câmara dos Deputados. Relatório Anual da Comissão de Direitos Humanos e

Minorias. Brasília: Câmara dos Deputados, 2000. 148 p.

Câmara dos Deputados. Relatório Anual da Comissão de Direitos Humanos e

Minorias. Brasília: Câmara dos Deputados, 2001. 208 p.

Câmara dos Deputados. Relatório Anual da Comissão de Direitos Humanos e

Minorias. Brasília: Câmara dos Deputados, 2002. 348 p.

Câmara dos Deputados. Relatório Anual da Comissão de Direitos Humanos e

Minorias. Brasília: Câmara dos Deputados, 2003. 93 p.

Câmara dos Deputados. Relatório Anual da Comissão de Direitos Humanos e

Minorias. Brasília: Câmara dos Deputados, 2004. 214 p.

Câmara dos Deputados. Relatório Anual da Comissão de Direitos Humanos e

Minorias. Brasília: Câmara dos Deputados, 2006. 123 p.

Câmara dos Deputados. Relatório Anual da Comissão de Direitos Humanos e

Minorias. Brasília: Câmara dos Deputados, 2007. 177 p.

Câmara dos Deputados. Relatório Anual da Comissão de Direitos Humanos e

Minorias. Brasília: Câmara dos Deputados, 2008. 107 p.

Câmara dos Deputados. Relatório Anual da Comissão de Direitos Humanos e

Minorias. Brasília: Câmara dos Deputados, 2009. 107 p.

Câmara dos Deputados. Relatório Anual da Comissão de Direitos Humanos e

Minorias. Brasília: Câmara dos Deputados, 2010. 133 p.

Câmara dos Deputados. Relatório Anual da Comissão de Direitos Humanos e

Minorias. Brasília: Câmara dos Deputados, 2011. 34 p.

Câmara dos Deputados. Relatório Anual da Comissão de Direitos Humanos e

Minorias. Brasília: Câmara dos Deputados, 2012. 67 p.

Câmara dos Deputados. Relatório Anual da Comissão de Direitos Humanos e

Minorias. Brasília: Câmara dos Deputados, 2013. 105 p.

Câmara dos Deputados. Relatório Anual da Comissão de Direitos Humanos e

Minorias. Brasília: Câmara dos Deputados, 2014. 36 p.

. Câmara dos Deputados. Relatório Anual da Comissão de Direitos Humanos e

Minorias. Brasília: Câmara dos Deputados, 2015. 153 p.

Câmara dos Deputados. Relatório Anual da Comissão de Direitos Humanos e

Minorias. Brasília: Câmara dos Deputados, 2016. 184 p.

Câmara dos Deputados. Relatório Anual da Comissão de Direitos Humanos e

Minorias. Brasília: Câmara dos Deputados, 2017. 127 p. 
FERRAZ JÚNIOR, T. S. Introdução ao estudo do direito: técnica, decisão, dominação. 5. ed. São Paulo: Atlas, 2007.

FIGUEIREDO, A.; LIMONGI, F. Mudança Constitucional, Desempenho do Legislativo e Consolidação Institucional. Revista Brasileira de Ciências Sociais, São Paulo, ano 10, n. 29, p. 175-200, 1995.

FIGUEIREDO, A.; SANTOS, F. Estudos Legislativos no Brasil. In: AVRITZER, Leonardo; MILANI, Carlos; BRAGA, Maria do Socorro (org.). A Ciência Política no Brasil: 1960-2015. Rio de Janeiro: FGV Editora, 2016.

MCCUBBINS, M. D.; SHWARTZ, T. Congressional Oversight Overlooked: Police Patrols versus Fire Alarms. American Journal of Political Science, Charlottesville, v. 28, n. 1, p. 165179, Feb. 1984. Disponivel em: http://www.jstor.org/stable/2110792. Acesso em: 31 ago. 2017.

MOREIRA NETO, D. D. F. Legitimidade e discricionariedade: novas reflexões sobre os limites e controle da discricionariedade. 2. ed. Rio de Janeiro: Forense, 1991.

MORONI, J. A. O direito à participação no governo Lula. In: AVRITZER, L. Experiências nacionais em participação social. São Paulo: Cortez, 2009.

NÉRI, Felipe. Marco Feliciano é eleito presidente da Comissão de Direitos Humanos. Portal G1 de Notícias, 07/03/2013. Disponível em:

http://g1.globo.com/politica/noticia/2013/03/marco-feliciano-e-eleito-presidente-dacomissao-de-direitos-humanos.html Acesso em 08/10/2019.

PEREIRA, C.; MUELLER, B. Uma teoria da preponderância do poder executivo. O sistema de comissões no legislativo brasileiro. Revista Brasileira de Ciências Sociais, São Paulo, v. 15, n. 43, p. 45-67, jun. 2000. Disponivel em:

http://portal.anpocs.org/portal/index.php?option=com_content \&view=article\&id=193:rbcs43\&catid=69:rbcs\&Itemid=399. Acesso em: 7 dez. 2015.

PIOVESAN, F. Direito ao desenvolvimento. In: PRONER, C.; CORREAS, O. Teoria crítica dos direitos humanos: in memorian Joaquin Herrera Flores. Belo Horizonte: Fórum, 2011. 278 p.

POGREBINSCHI, T.; SANTOS, F. Participação como Representação: O Impacto das Conferências Nacionais de Políticas Públicas no Congresso Nacional. Dados, Rio de Janeiro, v. 54, n. 3, p. 259-304, 2011.

ROCHA, M. M. Informação e deliberação no processo legislativo estadual: o caso da ALMG. In: SANTOS, Manoel Leonardo; ANASTASIA, Fátima. (org.). Política e desenvolvimento institucional no Legislativo de Minas Gerais. 1. ed. Belo Horizonte: Editora PUC/MG, 2016. p. 241-280.

SANTOS, F. O poder legisaltivo no presidencialismo de coalizão. Belo Horizonte: Rio de Janeiro: UFMG/IUPERJ, 2003.

SOARES, E. A audiência pública no processo administrativo. Revista de Direito Administrativo, Rio de Janeiro, n. 229, p. 259-283, jul./set. 2002.

Artigo recebido em: 2019-04-16

Artigo reapresentado em: 2019-06-19

Artigo aceito para publicação em: 2019-06-24 